\title{
PROGRAM PENGEMBANGAN BUDAYA KEWIRAUSAHAAN \\ BAGI MAHASISWA PERGURUAN TINGGI MELALUI \\ KETERAMPILAN PERCETAKAN
}

\author{
Rubino Rubiyanto \\ Fakultas Keguruan dan Ilmu Pendidikan \\ Universitas Muhammadiyah Surakarta
}

\section{ABSTRACT}

Untill predominate out-comes of the College are job seeker. To change the mind set them to become the job creator presumably need an effort, stock purchasing and giving of capital entrepreneur. Therefore no its bad if the student FKIP to made as a professional teacher candidate, also given entrepreneur lecturer. This lecturer is programmed in an package: KWU in the field of offset printing skill. Target of this activity is: (a) develop the culture of entrepreneur in PT, (b) the student have the stock of science and skill of offset printing area, (c) student have the knowledge about trick of the trade, developing idea of effort, managing effort, marketing strategy and obtain;get the capital employed, (d) student have the readiness of business. The target of this activity are 30 student's of FKIP in semester VI from various program. Lecturing method cover the discourse, discussion, duty, question and answer, compilation of proposal business, seminar proposal, simulation and also practice in printing office. Resistance met by execution KWU at the same time by lecturer fundamental so that execution entrepreneur delayed. Finally the enterpreur program are executed after even semester test 2006 finishing. Activity exterior for example; 1) piled up over by module entrepreneur, vision of business mission, career tuition, credit system of this effort; 2) piled up over by proposal business in group; 3) the expected after student pass, $25 \%$ participant earn the entrepreneur offset printing.

Kata kunci: cetak offset, keterampilan, wirausaha.

\section{PENDAHULUAN}

Dalam suasana perekonomiaan yang memprihatinkan saat ini di mana jumlah lapangan pekerjaan sulit dicari, angka pengangguran yang cukup tinggi,

76 WARTA, Vol .10, No. 1, Maret 2007: 76 - 83 
orang biasanya bekerja asal mendapatkan makan dengan tidak dipikirkan kualitas kerja serta upah yang diterima. Tidak sedikit orang bertindak berusaha untuk mendapatkan uang dengan jalan berwirausaha. Berwirausaha adalah suatu upaya jalan pintas untuk mendapatkan pekerjaan secara mandiri, bangkit, dan berani untuk berdiri sendiri. Berwirausaha telah terbukti sebagai penyelamat perekonomian bangsa di kala bangsa ini mengalami krisis perekonomian yang baru lalu, di samping juga memiliki nilai positif yaitu mengurangi jumlah pengangguran.

Berkaitan dengan program pengembangan budaya kewirausahaan di Perguruan Tinggi, banyak kemampuaan atau keterampilan produktif yang relevan untuk dilatihkan kepada mahasiswa. Mahasiswa Fakultas Keguruan dan Ilmu Pendidikan(FKIP) yang secara institusional dipersiapkan sebagai calon guru tidak ada jeleknya diberikan pula kuliah kewirausahaan. Hal ini diharapkan bahwa lulusan FKIP selain dipersiapkan sebagai calon guru, diharapkan pula disela-sela waktu yang tersisa dipergunakan untuk mengembangkan jiwa kewirausahaan. Pertanyaan yang muncul adalah apakah mahasiswa sudah dipersiapkan demikiaan. Untuk itulah diperlukan kuliah kewirausahaan di perguruan tingi.

Memperhatikan pertimbangan di atas, jika mahasiswa FKIP diberikan pelatihan keterampilan dalam bentuk mata kuliah kewirausahaan sampai pada taraf dapat menghasilkan karya alternatif, mereka akan memiliki keterampilan dalam bidang kejuruan, dan bidang jasa industri sehingga dapat memberikan alternatif lapangan pekerjaan bagi mahasiswa yaitu berwirausaha. Keuntungan lain yang dapat dipetik jika mereka telah menjadi guru akan dapat mendidik generasi mudanya untuk berwirausaha.

Kuliah kewirausahaan khususnya dalam bidang percetakan offset sebagai salah satu wahana pelatihan kewirausahaan bidang keterampilan produktif yang merupakan alternatif menarik untuk dipilih guna meningkatkan keterampilan mahasiswa, karena dapat memberikan pengalaman nyata mengenai kewirausahaan dan pengelolaannya dalam suatu keterampilan berwirausaha. Alasan lain dipilihnya alternatif percetakan offset adalah: (1) prospek keterampilan cetak offset memiliki masa depan cerah, (2) lembagalembaga pendidikan, masyarakat dan industri sangat membutuhkan produk atau hasil cetakan, (3) usaha cetak offset kecil-kecilan tidak memerlukan modal dan peralatan yang mahal, (4) bahan bakunya mudah diperoleh.

Program Pengembangan ... (Rubino Rubiyanto) 


\section{Tujuan khusus, targed luaran dan manfaat kegiatan.}

1. Tujuan khusus:

a. Mengembangkan budaya kewirausahaan di Perguruan Tinggi

b. Mengembangkan jiwa kewirausahaan mahasiswa.

c. Mahasiswa memperoleh pengetahuan tentang bagaimana mengembangkan ide usaha, memperoleh modal usaha, mengelola usaha, strategi pemasaran yang baik, merintis usaha serta mengembangkan usaha.

d. Mahasiswa memiliki bekal dan kesiapan bisnis cetak offset.

e. Menambah jumlah wirausahawan baru dalam bidang cetak offset.

2. Target luaran kegiatan

a. Modul Kuliah Kewirausahaan, visi, misi dan penyusunan rencana bisnis: bimbingan karier dan sistem kredit usaha.

b. Tersusun proposal bisnis yang dirancang kelompok mahasiswa.

c. Tersusun sumber daya dan praktisi dilapangan yang peduli terhadap usaha cetak offset

d. Diharapkan setelah mahasiswa lulus studi; $25 \%$ di antaranya menjadi wirausaha baru.

3. Manfaat kegiatan:

a. Membuka cakrawala baru dalam pemikiran mahasiswa.

b. Merintis kuliah kewirausahaan di PT yang selama ini belum berkembang.

c. Menumbuh kembangkan minat berwirausaha pada mahasiswa.

d. Mengenalkan dunia usaha khususnya cetak offset pada mahasiswa.

\section{RANCANGAN BAHAN AJAR}

\begin{tabular}{|c|l|l|l|}
\hline $\begin{array}{c}\text { Pertemuan } \\
\text { ke }\end{array}$ & \multicolumn{1}{|c|}{ Materi Kuliah } & \multicolumn{1}{c|}{ Metode } & \multicolumn{1}{c|}{ Dosen } \\
\hline 1 & $\begin{array}{l}\text { Hakikat Kewirausahaan } \\
\text { Profil Wirausaha, Sifat Pribadi/ } \\
\text { Utama, Konsep 10 D. }\end{array}$ & $\begin{array}{l}\text { Ceramah, Disksusi, } \\
\text { Tugas, Laporan }\end{array}$ & Rubino R, M.Pd. \\
\hline 2 & $\begin{array}{l}\text { Penentuan Visi, Misi, Tujuan } \\
\text { Bisnis } \\
\text { Studi Kelayakan }\end{array}$ & $\begin{array}{l}\text { Cearamah, Diskusi } \\
\text { Tugas }\end{array}$ & M.Yahya, M.Si. \\
\hline 3 & $\begin{array}{l}\text { Bimbingan Karir } \\
\text { Merencanakan Karir } \\
\text { Langkah-langkah Menuju Sukses }\end{array}$ & $\begin{array}{l}\text { Ceramah } \\
\text { Diskusi } \\
\text { Tugas }\end{array}$ & $\begin{array}{l}\text { Saring, Marsudi, } \\
\text { M.Pd. }\end{array}$ \\
\hline
\end{tabular}

78 WARTA, Vol .10, No. 1, Maret 2007: 76 - 83 


\begin{tabular}{|c|c|c|c|}
\hline 4 & $\begin{array}{l}\text { Kewirausahaan } \\
\text { Mengenal Dunia Usaha } \\
\text { Mengembangkan Ide \& Hobi }\end{array}$ & $\begin{array}{l}\text { Ceramah, Tugas } \\
\text { Pelaporan }\end{array}$ & Rubino, R, M.Pd. \\
\hline 5 & $\begin{array}{l}\text { Perencanaan Usaha dan Penyu- } \\
\text { sunan Rencana Bisnis, Memilih } \\
\text { Usaha }\end{array}$ & $\begin{array}{l}\text { Ceramah } \\
\text { Tanya Jawab, } \\
\text { Tugas }\end{array}$ & Sofyan Anif, M.Si. \\
\hline 6 & $\begin{array}{l}\text { Sistem Informasi Manajemen } \\
\text { Strategi Bisnis. }\end{array}$ & Ceramah, Tugas & $\begin{array}{l}\text { Dinas Perindag } \\
\text { Kota Surakarta }\end{array}$ \\
\hline 7 & $\begin{array}{l}\text { Kewirausahaan } \\
\text { Merintis Usaha, Membangun } \\
\text { Usaha Mandiri }\end{array}$ & $\begin{array}{l}\text { Taanya jawaab } \\
\text { Diskusi }\end{array}$ & Rubino, R.M.Pd. \\
\hline 8 & $\begin{array}{l}\text { Sistem Informasi Manajmen \& } \\
\text { Teknik Pengambilan Keputusan }\end{array}$ & Ceramaah, Diskusi & Sofyan Anif, M.Si. \\
\hline 9 & Ujian Tengah Semester & $\begin{array}{l}\text { Pengumpulan } \\
\text { Tugas }\end{array}$ & Tim Pelaksana \\
\hline 10 & Bimbingan Karir & Tanya jawab & $\begin{array}{l}\text { Saring } \quad \text { Marsudi, } \\
\text { M.Pd. }\end{array}$ \\
\hline 11 & $\begin{array}{l}\text { Sistem Pencatatan Keuangan, } \\
\text { Permodalan } \\
\text { Permohonan Kredit \& Analisis } \\
\text { Kredit }\end{array}$ & $\begin{array}{l}\text { Diskusi, Ceramaah } \\
\text { Tanya Jawab }\end{array}$ & $\begin{array}{l}\text { BPD Jateng Capem } \\
\text { UMS. }\end{array}$ \\
\hline 12 & Etika Bisnis & Ceramah, Diskusi & M.Yahya, M.Si. \\
\hline 13 & $\begin{array}{ll}\text { Teori dan } & \text { Keterampilan } \text { Cetak } \\
\text { Offset } & \\
\text { Pengertian, } & \text { Peralatan, Langkah } \\
\text { Kerja } & \end{array}$ & $\begin{array}{ll}\text { Ceramah, } & \text { Tugas } \\
\text { Lapangan } & \end{array}$ & $\begin{array}{ll}\text { Praktisi } & \text { Cetak } \\
\text { Offset } & \end{array}$ \\
\hline 14 & Pendalaman Cetak Offset & Tugas Lapangan & Praktisi \\
\hline 15 & Presentase Rencana Bisnis & Seminar, Diskusi & Tim Pelakana \\
\hline 16 & Kunjungan ke Percetakan & $\begin{array}{l}\text { Observasi } \\
\text { Praktik }\end{array}$ & Tim Pelaksana \\
\hline 17 & Pengumpulan Tugas/Ujian Tulis & & Tim Pelaksana \\
\hline
\end{tabular}

\section{METODE PERKULIAHAN DAN EVALUASI}

Metode perkuliahan diserahkan kepada masing-masing dosen mata kuliah. Namun diperkirakan mereka akan menggunakan ceramah, diskusi, tanya jawab, simulasi bahkan ada yang menggunakan demonstrasi, diakhiri dengan kunjungan ke objek studi di percetakan offset di mana pemilikinya sekaligus menjadi dosen tamu pada pelaksanaan KWU. Khusus rencana Usaha Bisnis (business plann) dijelaskan secaraumum di bagaian awal perkuliahan dengan maksud memberikan waktu yang cukup kepada peserta agar dapat merencanakan dengan baik. Hal ini sejalan dengan kenyataan di lapangan bahwa rencana bisnis merupakan sinergi dari komponen-komponen perkuliahan yang barangkali sangat mungkin direvisi serta diperbaiki dari waktu ke waktu. 
Evaluasi pembelajaraan terdiri dari evaluasi intemal danjika memungkinkan dilakukan evaluasi eksternal. Evaluasi internal terdiri dari tanggapan dan hasil kuliah peserta program KWU. Evaluasi tanggapan dilakukan dengan jalan membagikan angket kepada peserta untuk merespon terhadap rancangan mata kuliah, pemilihan dosen, pelaksanaan perkuliahan serta tanggapan peserta terhadap program kewirausahaan mahasiswa. Angket dirancang mencakup aspek substansi antara lain kualitas dosen dan pembicara tamu, kualitas pemilihan serta pengembangan materi ajar, alat bantu sampai pada layanan kunjungan ke objek percetakan dan terkait dengan penyelenggaraan program kewirausahaan.

Evaluasi hasil belajar dilakukan dengan prinsip-prinsip sebagai berikut:

1. Evaluasi dilakukan secara kontinyu selama perkuliahan berlangsung dan pada setiap akhir topik melalui tes lisan maupun tertulis.

2. Evaluasi dilakukan juga dengan memberikan tugas-tugas rumah sesuai dengan topik perkuliahan.

3. Evaluasi dilakukan juga dengan penyampaian rencana bisnis yang disusun secara kelompok oleh mahasiswa dihadiri oleh praktisi dan dosen pembimbing. 4. Nilai akhir mahasiswa ditentukan berdasar: a) respon mahasiswa selama proses pembelajaran (10\%); b) tugas rumah (20\%); c) penulisan rencana bisnis (40\%); dan d) ujian akhir (30\%).

\section{PELAKSANAAN}

\section{Persiapan}

Pada tahap persiapan ada tiga kegiatan yaitu: koordinasi tim peleksana, perekrutan calon mahasiswa, dan penyusunan jadwal kuliah.

Koordinasi tim pelaksana, selaku ketua tim perlu melakukan koordinasi dengan pihak-pihak yang terkait, misalnya dengan pimpinan FKIP pembantu dekan bidang kemahasiswaan dan beberapa dosen yang terlibat dalam perkuliahan. Agenda kegiatan pada koordinasi ini meliputi: a) penyampaian program KWU pada pimpinan FKIP; b) peminjaman ruang kuliah dan fasilitas perkuliahan (spidol, OHP, white board); c) strategi perekrutan peserta program; d) perekrutan dosen dan dosen tamu; e) rencana kunjungan ke praktisi / percetakan.

Perekrutan mahasiswa peserta KWU dilakukan dengan beberapa strategi antara lain: (1) penempelan papan pengumuman di tempat yang srategis; (2) permohonaan kepada setiap jurusan agar mengirimkan 6 mahasiswa semester VI ke atas yang berminat untuk mengikuti program 
KWU bidang cetak offset; (3) pendaftaran peserta dipusatkan pada pembantu dekan bidang administrasi (II) dan atau ke Sdr Drs.Rubino Rubiyanto, M.Pd. dosen pendidikan matematika FKIP-UMS; dan (4) pendaftaran berlangsung sampai akhir Maret 2006.

Adapun syarat pendaftaran adalah: a) mahasiswa semester VI ke atas; b) berminat bidang cetak offset; c) sanggup mengikuti kuliah dengan tertib; d) mengisi blanko pendaftaran; dan e) tidak dipungut biaya.

\section{Pelaksanaan}

Laporan dari seksi pendaftaraan sampai pada tanggal 15 Maret 2006 baru tercatat 11 orang mahasiswa. Hal ini dirasa masih jauh dari target yang diinginkan. Kuliah perdana yang direncanakan dimulai 18 Maret 2006 ditunda. Pendaftaran peserta diperpanjang sampai pada akhir bulan Maret dengan harapan jumlah peserta terpenuhi. Rencana perkuliahan dapat dimulai 1 April 2006. Perpanjangan waktu ini juga dipergunakan untuk kordinasi dengan jurusan agar setiap jurusan mengirimkan calon mahasiswa peserta KWU. Sampai pada batas waktu yang telah disepakati jumlah peserta juga tidak berubah. Disimpulkan perkuliahan dimulai 1 April 2006, sambil berusaha memenuhi target peserta KWU.

Kuliah perdana dimulai Sabtu, 1April 2006, peserta 6 orang mahasiswa. Pada hari kedua diikuti oleh 4 orang mahasiswa dan pada hari ketiga tidak ada mahasiswa yang masuk. Oleh karena itu kuliah periode pertama terpaksa dibatalkan. Beberapa analisis kemungkinan yang muncul: a) pelaksanaan perkuliahan bersamaan dengan kuliah pokok; b) informasi kurang dapat merata; dan c) hari Sabtu merupakan hari yang sering dipergunakan oleh mahasiswa untuk pulang ke kampung halamannya. Hal-hal ini barangkali menjadi sebab mengapa jumlah mahasiswa peserta program KWU tidak memenuhi target. Disimpulkan bahwa pelaksanaan kuliah ditunda sampai mahasiswa selesai ujian semester genap 2005-2006.

Selaku ketua tim pelaksana selalu berpikir bagaimana terobosan yang perlu dilakukan agar program KWU dapat berjalan. Dengan persetujuan Dekan akhirnya disepakati kebijakan sebagai berikut: (a) mengerahkan kelas binaan ketua tim pelaksana (progdi matematika semester VI D); (b) pelaksanaan kuliah akan dimulai setelah ujian semester genap 2006; (c) kuliah akan dilaksanakan dengan pemadatan, dilaksanakan selama satu minggu, setiap hari dari pukul 07.30 sampai dengan pukul 12.00. Kebijakan 
terakhir inilah yang digunakaan sebagai pelaksanaan program KWU sehingga dapat berjalan dengan baik.

\section{HASIL EVALUASI AKHIR PROGRAM KWU, 2006.}

\begin{tabular}{|c|c|c|c|c|}
\hline No & NIM & Nama Mahasiswa & Tempat \& Tanggal Lahir & Nilai Akhir \\
\hline 1 & A410040057 & Hidayah Adi Romania & Sragen, 1 Juli 1986 & $\mathrm{~B}$ \\
\hline 2 & A410030058 & Si Hajiati & Pemalang, 26 Agustus 1985 & $\mathrm{~B}$ \\
\hline 3 & A410030061 & Ice Pondra W & Klaten, 9 Oktober 1984 & B \\
\hline 4 & A410030062 & Mariana Dewi Lestasi & Wonogiri, 24 Maret 1986 & A \\
\hline 5 & A410030064 & Luluk Khoiru K & Purwodadi, 27 Maret 1985 & $\mathrm{~B}$ \\
\hline 6 & A410030065 & Eka Istiyarini & Boyolali, 9 September 1985 & $\mathrm{~B}$ \\
\hline 7 & A410030066 & Edi Winarto & Karanganyar , 7 Juli 1985 & $\mathrm{~A}$ \\
\hline 8 & A410030068 & Kusnandar & Pati, 12 Juni 1987 & A \\
\hline 9 & A410030069 & Ari Prasetyowati & Karaanganyar, 27 Febr-1987 & B \\
\hline 10 & A410030070 & Tri Widyastuti & Sukoharjo, 20 Desember 1984 & $\mathrm{~B}$ \\
\hline 11 & A410030071 & Dimas Pujo P. & Jeporo, 29 Nopember 1985 & $\bar{A}$ \\
\hline 12 & A410030073 & Mahkfuddin & Boyolali, 7 April 1984 & $\mathrm{~B}$ \\
\hline 13 & A410030074 & Wahyudi & Wonogiri, 6 Desember 1984 & $\mathrm{~B}$ \\
\hline 14 & A410030076 & Sony Kukuh Prasetyo & Sragen 7 Desember 1984 & $\bar{A}$ \\
\hline 15 & A410030078 & Endah Setyorini & Kendal, 6 Februari 1986 & A \\
\hline 16 & A410030169 & M.Zulkarnaen & Pemalang, 6 November 1985 & A \\
\hline 17 & A410030085 & Anita Nurhaidayati & Wonogiri, 31 Agustus 1986 & B \\
\hline 18 & A410030077 & Ratih Dwi Praswati & Pekalongan, 16 April 1986 & $\mathrm{~B}$ \\
\hline 19 & A410030080 & Iin Marlinda & Boyolli, 26 Juli 1986 & A \\
\hline 20 & A410030082 & Nur Hariyadi & Wonogiri, 4 Desember 1985 & $\mathrm{~B}$ \\
\hline 21 & A410030086 & Nur Sita F & Wonogiri, 23 Februari 1985 & A \\
\hline 22 & A410030088 & Roy Kasmarin & Cirebon, 20 Januari 1986 & A \\
\hline 23 & A410030098 & Yahya Widyastuti & Boyolali, 17 Desember 1986 & $\mathrm{~B}$ \\
\hline 24 & A410030094 & Era Prasetyo DA & BoyolLI, 16 April 1986 & A \\
\hline 25 & A410030096 & Ika Kartika sari & Grobogan, 31 Januari,1987 & A \\
\hline 26 & A410030099 & Iswanti & Sukoharjo, 13 Maret 1984 & A \\
\hline 27 & A410030100 & Anik Trisnawati & Klaten, 10 Januari 1986 & $\mathrm{~B}$ \\
\hline 28 & A410030093 & Ria Noviana Agus & Klaten, 8 November 1986 & A \\
\hline 29 & A410030115 & Amin Mustofa & Grobogan, 3 Maret 1984 & A \\
\hline 30 & A410030097 & Maya Dewi Maninten & Sukoharjo, 25 Agust 1985 & $\mathrm{~B}$ \\
\hline 31 & A410030089 & Mayang Sirda & Pati, 20 Juni 1987 & $\bar{A}$ \\
\hline 32 & A410030166 & Sri Sumiyati & Klaten, 4 Oktober 1985 & $\mathrm{~A}$ \\
\hline
\end{tabular}

Catatan : Nilai akhir merupakan nilai rata-rata dari

Nilai ujian, praktek, seminar proposal busnis plan

Dan studi kancah.

82 WARTA, Vol .10, No. 1, Maret 2007: 76 - 83 


\section{SIMPULAN}

1. Kegiatan KWU baru pertama kali diadakan

2. Mahasiswa masih perlu motivasi untukmengembangkanjiwa kewirausahaan

3. Kuliah kewirausahaan di FKIP dikuti oleh 32 peserta.

4. Kuliah dimulai 3 Juli 2006 (setelah ujian semester selesai).

5. Pelaksanaan kuliah dilakukan pemadatan materi

6. Materi kuliahmeliputi:KWU, Bimbingan Karir, Perencanaan Usaha, Business Plann, SIM, Sistem Pencatatan Keuangan, Etika Bisnis, Cetak Offset, Strategi bisnis, Sistem Pencatatan Keuangan, Proposal Kredit, kunjungan ke percetakan Kalam Offset.

\section{DAFTAR PUSTAKA}

Idrus. 1993. Kiat Sukses Mencari Kerja. Pekalongan: CV Bahagia.

Musrofi. 2003. Kunci Sukses Berwirausaha. Jakarta: Elex Media Komputindo Kelompok Gramedia Jakarta.

Suardiman. 1985. Menuju Ke Kehidupan Wiraswasta Berhasil. Yogyakarta: Studing

Subanar Harimurti. 1998. Manajemen Usaha Kecil. Yogyakarta: Gajahmada University Press.

Sudiyono. 2006. Hand-Out Kewirausahaan. Yogyakarta: Fakultas Teknik Industri UAD

Tim P3HP dan Kewirausahaan LPM UNY. 2003. Pedoman Pelaksanaan Pengembangan Budaya Kewirausahaan, Penerapan Ipteks dan Vucer. Yogyakarta: Lembaga Pengabdian Kepada Masyarakat Universitas Negeri Yogyakarta.

. 2002. Pola Pendidikan Berorientasi Kecakapan Hidup (Life Skill). Yogyakarta: Proyek Peningkatan Sumberdaya Pendidikan Sekolah Menengah Umum Daerah Istimewa Yogyakarta. Makalah, disajikaan pada Pelaksanaan Pelatihan/Diklat Pendalaman Materi Mata Pelajaran Sistem Evaluasi Dinas Pendidikan Propinsi DIY. 
84 WARTA, Vol .10, No. 1, Maret 2007: 76 - 83 
86 WARTA, Vol .10, No. 1, Maret 2007: 76 - 83 